\title{
The effect of endodontic chemicals on the retention of fiber posts luted using a self-adhesive cement
}

\author{
Patrícia dos Santos Jardim ${ }^{1 *}$, Tatiana Pereira-Cenci ${ }^{1}$, Crissie Felicetti Badin ${ }^{1}$, Ana Cláudia de Araújo Ferreira ${ }^{1}$ \\ and Rogério Castilho Jacinto ${ }^{2}$
}

\author{
* Correspondence: \\ patriciajardim.ufpel@gmail.com \\ ${ }^{1}$ Department of Operative \\ Dentistry, School of Dentistry, \\ Federal University of Pelotas, \\ Pelotas, RS, Brazil \\ Full list of author information is \\ available at the end of the article
}

\begin{abstract}
The aim of this study was to assess the effect of endodontic chemical substances on the retention of fiber posts luted using a self-adhesive cement. Single-canal human roots of 75 teeth were divided into 5 groups $(n=15)$. Root canals were instrumented with one of the following substances: $0.9 \% \mathrm{NaCl}$ (control); $5.25 \%$ sodium hypochlorite; $5.25 \%$ Sodium hypochlorite + 17\% EDTA; $2 \%$ chlorhexidine gel; $2 \%$ chlorhexidine gel $+17 \%$ EDTA. After chemo-mechanical preparation, fiber post cementation was performed with self-adhesive resin cement (RelyX Unicem, 3 M/ESPE). One-way ANOVA was performed followed by a multiple comparison Tukey post hoc test $(a=5 \%)$. The use of $2 \%$ chlorhexidine gel resulted bond strength statistically similar to the control group ( $p=0.418$ ), which was higher than the other groups. A final irrigation with $17 \%$ EDTA significantly reduced bond strength $(p<0.001)$. The use of $5.25 \%$ sodium hypochlorite negatively affected the bond strength, either with or without a final irrigation with $17 \%$ EDTA $(p<0.001)$. Our results suggest that $2 \%$ chlorhexidine gel used during endodontic chemo-mechanical preparation, without a final irrigation with $17 \%$ EDTA, promotes a more favorable condition to the retention of fiber posts luted using a self-adhesive cement than $5.25 \%$ sodium hypochlorite.
\end{abstract}

Keywords: Chlorhexidine; EDTA; Fiber glass posts; Push out; Resin cement

\section{Springer}

\section{Background}

Glass-fiber posts are an important clinical option to provide retention for coronal dental restorations, as they have the elastic modulus is similar to that of dentin, and are cemented by an adhesive technique [1].

The debonding at the dentin/cement interface has been considered the major cause of fiber post restorations failure [2,3]. Thus, a propitious environment for both root dentin hybridization and stability of the bond strength must be intended.

One of the factors affecting the bond strength of fiber posts is the chemical substance used for biomechanical preparation of root canals [4]. The most commonly used substance in endodontic treatment is sodium hypochlorite $(\mathrm{NaOCl})$, in various concentrations, due to its known antibacterial activity and its capability of dissolving organic tissues [5-7]. Currently, however, $2 \%$ chlorhexidine (CHX) gel has been widely used as an alternative auxiliary substance to root canal treatment due to properties

(C) 2014 Jardim et al.; licensee Springer. This is an Open Access article distributed under the terms of the Creative Commons

Attribution License (http://creativecommons.org/licenses/by/2.0), which permits unrestricted use, distribution, and reproduction in any medium, provided the original work is properly cited. 
such as broad antimicrobial spectrum, substantivity, and low cytotoxicity [8,9]. Moreover, endodontic protocols indicate the application of $17 \%$ Ethylene diamine tetracetic acid (EDTA) as a final irrigating solution, in order to promote an appropriate cleaning of the root canal walls, consequently, improving the penetration of chemical substances and promoting a better contact between the dentin walls and filling material $[10,11]$.

It has been shown that $2 \% \mathrm{CHX}$ gel does not interfere with the collagen present in the organic matrix of root dentin, while $5.25 \% \mathrm{NaOCl}$, whether associated or not with 17\% EDTA, causes birefringence alterations of dentin collagen [12]. The preservation of the collagen fibrils is essential for the adhesion of resin materials to dentin, as they promote micromechanical retention and participate in the process of chemical union between the hydroxyapatite present in collagen fibers and some self-etching adhesive materials [13].

The pre-treatment of dentin surface with $\mathrm{CHX}$ has been shown to reduce the bond strength of self-adhesive resin cements to dentin [14]. On the other hand, a final rinse with CHX did not affect the immediate push-out bond strength in post bond cementation with self-adhesive resin cements [15]. However, the performance of chemical substances used for biomechanical preparation of the root canals on the bond strength of self-etching adhesive resin cements remains unknown. Hence, the aim of this study was to evaluate the effect of the substances used as endodontic auxiliary chemical substances, $5.25 \% \mathrm{NaOCl}$ and $2 \% \mathrm{CHX}$ gel and their association with 17\% EDTA on the retention of fiber posts luted using a self-adhesive cement. The study tested the null hypothesis that endodontic substances do not affect the bond strength of fiber posts cemented with self-adhesive resin cement.

\section{Methods}

This study was approved by the Local Research and Ethics Committee of the Federal University of Pelotas (150/2010). Single rooted caries-free human teeth were obtained and examined. Roots with open apices and resorptive defects were excluded and seventy-five teeth were randomly divided into five groups $(\mathrm{n}=15)$, according to the endodontic substance used.

Teeth were mechanically cleaned with a curette to remove soft tissue remnants from the root surfaces. The teeth were decoronated at the cementoenamel junction (CEJ) with a double-sided diamond disk (Isomet, Buehler, Lake Bluff, IL, USA) in low-speed rotary instrument under constant water-cooling, in order to leave $15 \mathrm{~mm}$ of root length. A size $10 \mathrm{~K}$-file (Dentsply Maillefer, Ballaigues, Switzerland) was used to create an apical stop with a step-back preparation. Working length was determined by placing the instrument into the canal until visible at the apical foramen and subtracting $1 \mathrm{~mm}$ from this length. The cervical portion of the root was prepared with Gattes-Gliden drills up to $11 \mathrm{~mm}$. Next, the root canals were instrumented with K-flex endodontic files (Maillefer/ Dentsply) in sequence up to $\mathrm{K}=50$ associated to the previously determined substance for each group, as follows: $0.9 \% \mathrm{NaCl}$ (control), $2 \% \mathrm{CHX}$ gel, $2 \% \mathrm{CHX}$ gel with final irrigation with $17 \%$ EDTA, $5.25 \% \mathrm{NaOCl}$ and $5.25 \% \mathrm{NaOCl}$ with final irrigation with $17 \%$ EDTA. The working time was standardized for each file $(1 \mathrm{~min})$, as well as the volume of the substance used $(30 \mathrm{~mL}$ of $0.9 \% \mathrm{NaCl}, 5.25 \% \mathrm{NaOCl}$ and 17\% EDTA; $3 \mathrm{~mL}$ of $2 \% \mathrm{CHX}$ gel followed by $30 \mathrm{~mL}$ of $0.9 \% \mathrm{NaCl}$ ).

When the endodontic preparation was complete, the root canals were prepared for fiber post cementation (\#0.5, White Post DC, FGM, Brazil) using the drill of the post 
system. The canals were thoroughly washed with saline solution and kept moist until use. Absorbent paper points were used to remove the excess of saline solution from the canals. Finally, the fiber post was previously prepared by cleaning with $70 \%$ ethanol, air-dried and silanized for $1 \mathrm{~min}$ and gently air dried for $5 \mathrm{~s}$ (Silano, Angelus, Brazil). The self-adhesive cement was prepared according to manufacturer's instructions and the resin cement was inserted into the root canal (RelyX Unicem, 3 M ESPE, St Paul, MN, USA). The fiber post was immediately placed to seat, excess of the cement was removed with a microbrush and the luting composite was light-cured for $60 \mathrm{~s}$ (Radii-Cal, SDI, Australia).

Specimens were then stored at $100 \%$ humidity and $37^{\circ} \mathrm{C}$ for $24 \mathrm{~h}$ to allow complete polymerization. The specimens were fixed on acrylic plates and then sectioned transversally into $1.5 \mathrm{~mm}$ slices containing cross sections of the fiber postsunder watercooling with a precision machine (Buehler Isomet, USA). The cervical and apical diameter of the canal and the thickness of all of the slices were measured with a digital caliper (Mitutoyo Digimatic Caliper, France).

\section{Push-out strength test}

Each section was marked on its apical side and positioned on a base, with a central hole, in a universal testing machine (DL2000, EMIC, São José dos Pinhais, PR, Brazil). The push-out test was performed by applying a compressive load to the apical side of each slice by using a $0.7-\mathrm{mm}$-diameter cylindrical plunger attached to theupper portion of the testing machine. A crosshead speed of $0.5 \mathrm{~mm} / \mathrm{min}$ was applied until bond failure occurred. The load upon failure was recorded in Newton $(\mathrm{N})$. The force required for dislocation of the post (bond strength) was calculated as follows: $F=R / A$, where $\mathrm{F}=$ force of displacement of the post $(\mathrm{N})$, and $\mathrm{A}=$ bond area $(\mathrm{mm} 2)$. Calculation of the bond area: $A=\pi . g .(R 1+R 2)$; where $\pi=3.14$; $g=$ taper of the root $[g=(h 2+(R 2-R 1) 2)$ 1 / 2]; R1 represents root opening in the apex and R2 represents the root opening in the cervical. R1 and R2 were measured in Image-J (Wayne Rasband, National Institutes of Health, Bethesda, MA, USA). Thickness of the slices (h) was measured with a digital caliper. The bond strength values of the tooth slices of each group were averaged for statistical analysis.

\section{Statistical analysis}

The data were analyzed using a statistical software package (R, Version 0.98 .490 - () 2009-2013 RStudio, Inc. USA). For comparison among chemical substances, one-way ANOVA was performed followed by a multiple comparison Tukey post hoc test. Statistical significance was considered as $\alpha=5 \%$.

\section{Results and discussion}

Table 1 shows the comparison among the five groups, which resulted in statistically significant differences $(\mathrm{p}<0.001)$. The use of $\mathrm{NaOCl}$ as a chemical substance resulted in the lowest bond strength $(\mathrm{p}<0.001)$. The same trend occurred with both groups with EDTA (either with $\mathrm{NaOCl}$ or $\mathrm{CHX} ; \mathrm{p}<0.001$ ). The group where CHX was used alone resulted in the same bond strength values as the control group $(\mathrm{NaCl} ; \mathrm{p}=0.455)$. The use of $2 \% \mathrm{CHX}$ gel did not affect the bond strength of the cement tested. However, the use of CHX gel with a final irrigation with 17\% EDTA 
Table 1 Mean \pm standard deviations push-out bond strength of glass fiber posts (in MPa)

\begin{tabular}{cr}
\hline Substance & Push-out \\
\hline Control & $14.0 \pm 8.1 \mathrm{~A}$ \\
\hline $\mathrm{NaOCl}$ & $5.3 \pm 3.3 \mathrm{~B}$ \\
\hline Chlorhexidine & $9.6 \pm 4.6 \mathrm{~A}$ \\
\hline $\mathrm{EDTA}+\mathrm{NaOCl}$ & $8.7 \pm 4.8 \mathrm{~B}$ \\
\hline EDTA + Chlorhexidine & $5.4 \pm 2.7 \mathrm{~B}$ \\
\hline
\end{tabular}

Upper case letter represents statistically significant differences among irrigants $(p<0.05)$.

significantly reduced the bond strength. The use of $5.25 \% \mathrm{NaOCl}$ negatively affected the bond strength of the cement tested, either with or without a final irrigation with $17 \%$ EDTA.

The use of $5.25 \% \mathrm{NaOCl}$ for chemo-mechanical preparation of root canals, either with or without a final irrigation with 17\% EDTA, presented statistically significant decrease on the bond strength of fiber post cemented with self-adhesive resin cement. The efficiency of adhesive systems is directly related to the dentin quality and collagen integrity. The fact that $\mathrm{NaOCl}$ is an efficient organic solvent that causes dissolution of dentin collagen fibrils $[12,16]$ might explain its negative influence on the bond strength of the self-adhesive resin cement shown in this study, since collagen plays an important role in the formation of the hybrid layer.

CHX gel has been widely used in endodontics and one of its most important features is not affecting the dentin collagen matrix [12]. The results of the present study indicate that $2 \% \mathrm{CHX}$ gel does not interfere with the bond strength of self-adhesive resin cements. On the other hand,it has been shown that when CHX solution was used as cavity cleanser, the residual solution and moisture contamination might be able to interfere with the bonding of RelyX Unicem to dentin, resulting in lower bond strengths [14]. Nevertheless, it is important to highlight that in the present study, $\mathrm{CHX}$ was used as a gel auxiliary to the root canal biochemical preparation and not as cavity cleanser solution.

The final application of 17\% EDTA after chemo-mechanical preparation with $2 \%$ CHX gel significantly reduced the bond strength. The application of EDTA reduces the $\mathrm{Ca}$ ions available on the surface of the canal walls; therefore, the potential chemical bonding that would be expected with self-adhesive resin cements is compromised affecting the final bond strength. The probable explanation is that the smear layer removal, promoted by the application of EDTA, facilitates resinous monomer penetration into the dentinal tubules [17].

Self-adhesive resin cements present a series of advantages on the bond of fiber posts, e.g. reduced clinical chair time, as they do not require any pre-treatment of the dental substrate, and elimination of the following steps: priming and air-drying for solvent evaporation [18-20]. However, the results of the present study showed that 5.25\% $\mathrm{NaOCl}$, either with or without $17 \%$ EDTA, affected the bond strength between selfadhesive resin cement and root canal dentin. Eventually, 2\% CHX gel promoted a more favorable condition to the cementation of fiber posts with self-adhesive resin cement than $5.25 \% \mathrm{NaOCl}$, and should be preferred in the root canal biomechanical preparation, without a final application of 17\% EDTA, when a fiber post is planned to be cemented with self-adhesive resin cement. 


\section{Conclusion}

The use of $2 \%$ chlorhexidine gel resulted on retention of fiber posts luted using a selfadhesive cement statistically similar to the control group $(\mathrm{p}=0.418)$, which was higher than the other groups. A final irrigation with 17\% EDTA significantly reduced on the retention of fiber posts luted using a self-adhesive cement. The use of $5.25 \% \mathrm{NaOCl}$ negatively affected the bond strength, either with or without a final irrigation with $17 \%$ EDTA.

\section{Competing interests}

The authors declare that they have no competing interests.

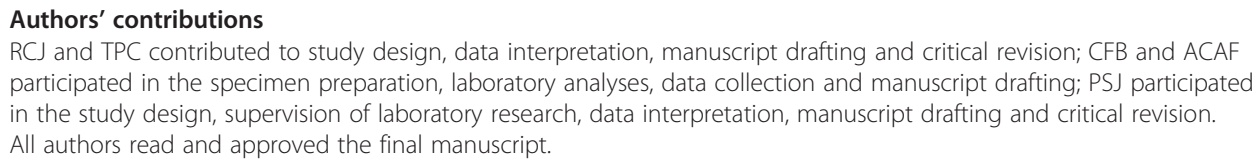

\section{Author details}

${ }^{1}$ Department of Operative Dentistry, School of Dentistry, Federal University of Pelotas, Pelotas, RS, Brazil.

${ }^{2}$ Department of Semiology and Clinics, School of Dentistry, Federal University of Pelotas, Pelotas, RS, Brazil.

Received: 13 November 2013 Accepted: 30 January 2014

Published: 04 Aug 2014

\section{References}

1. de Moraes AP, Cenci MS, Moraes RR, Pereira-Cenci T (2013) Current concepts on the use and adhesive bonding of glass-fiber posts in dentistry: a review. Appl Adhes Sci 1:4. doi:10.1186/2196-4351-1-4

2. Iglesia-Puig MA, Arellano-Cabornero A (2004) Fiber-reinforced post and core adapted to a previous metal ceramic crown. J Prosthet Dent 91:191-194. doi:10.1016/j.prosdent.2003.11.004

3. Grandini S, Goracci C, Monticelli F, Borracchini A, Ferrari M (2005) SEM evaluation of the cement layer thickness after luting two different posts. J Adhes Dent 7:235-240. doi:10.3290/j.jad.a10486

4. Farina AP, Cecchin D, Barbizam JV, Carlini-Júnior B (2011) Influence of endodontic irrigants on bond strength of a self-etching adhesive. Aust Endod J 37:26-30. doi:10.1111/j.1747-4477.2010.00249.x

5. Gomes BP, Ferraz CC, Vianna ME, Berber VB, Teixeira FB, Souza-Filho FJ (2001) In vitro antimicrobial activity of several concentrations of sodium hypochlorite and chlorhexidine gluconate in the elimination of Enterococcus faecalis. Int Endod J 34:424-428

6. Stojicic S, Zivkovic S, Qian W, Zhang H, Haapasalo M (2010) Tissue dissolution by sodium hypochlorite: effect of concentration, temperature, agitation, and surfactant. J Endod 36:1558-1562. doi:10.1016/ j.joen.2010.06.021

7. Shenoy A, Mandava P, Bolla N, Raj S, Kurien J, Prathap MS (2013) Antibacterial efficacy of sodium hypochlorite with a novel sonic agitation device. Indian J Dent Res 24:537-541. doi:10.4103/0970-9290.123361

8. Dametto FR, Ferraz CC, Gomes BP, Zaia AA, Teixeira FB, de Souza-Filho FJ (2005) In vitro assessment of the immediate and prolonged antimicrobial action of chlorhexidine gel as an endodontic irrigant against Enterococcus faecalis. Oral Surg Oral Med Oral Pathol Oral Radiol Endod 99:768-772. doi:10.1016/ j.tripleo.2004.08.026

9. Gomes BP, Vianna ME, Zaia AA, Almeida JF, Souza-Filho FJ, Ferraz CC (2013) Chlorhexidine in endodontics. Braz Dent J 24:89-102. doi:10.1590/0103-6440201302188

10. Johal S, Baumgartner JC, Marshall JG (2007) Comparison of the antimicrobial efficacy of 1.3\% NaOCl/BioPure MTAD to 5.25\% NaOCl/15\% EDTA for root canal irrigation. J Endod 33:48-51. doi:10.1016/j.joen.2006.08.007

11. Arslan H, YIlmaz CB, Karatas E, Barutcigil C, Topcuoglu HS, Yeter KY (2013) Efficacy of different treatments of root canal walls on the pull-out bond strength of the fiber posts. Lasers Med Sci, doi:10.1007/ s10103-013-1457-4

12. Moreira DM, Almeida JF, Ferraz CC, Gomes BP, Line SR, Zaia AA (2009) Structural analysis of bovine root dentin after use of different endodontics auxiliary chemical substances. J Endod 35:1023-1027. doi:10.1016/ j.joen.2009.04.002

13. Moodley D, Grobler SR (2002) Dentine bonding agents-a review of adhesion to dentine. J South Afr Dent Assoc 57:234-238

14. Hiraishi N, Yiu CK, King NM, Tay FR (2010) Effect of chlorhexidine incorporation into a self-etching primer on dentine bond strength of a luting cement. J Dent 38:496-502. doi:10.1016/j.jdent.2010.03.005

15. Gerth HU, Dammaschke T, Zuchner H, Schäfer E (2006) Chemical analysis and bonding reaction of RelyX Unicem and Bifix composites - a comparative study. Dent Mater 22:934-941. doi:10.1016/j.dental.2005.10.004

16. Ishizuka T, Kataoka H, Yoshioka T, Suda H, Iwasak N, Takahashi H, Nishimura F (2001) Effect of NaOCl treatment on bonding to root canal dentin using a new evaluation method. Dent Mater J 20:24-33

17. Miyasak K, Nakabayashi N (1999) Combination of EDTA conditioner and Phenyl-HEMA self-etching primer for bonding to dentin. Dent Mater 15:153-157. doi:10.1016/S0300-5712(99)00025-1 
18. Faria-e-Silva AL, Pedrosa-Filho CF, Menezes MS, Silveira DM, Martins LR (2009) Effect of relining on fiber post retention to root canal. J Appl Oral Sci 17:600-604. doi:10.1590/S1678-77572009000600012

19. Kececi AD, Ureyen KB, Adanir N (2008) Micro push-out bond strengths of four fiber-reinforced composite post systems and 2 luting materials. Oral Surg Oral Med Oral Pathol Oral Radiol Endod 105:121-128. doi:10.1016/ j.tripleo.2007.07.011

20. Radovic I, Monticelli F, Goracci C, Vulicevic ZR, Ferrari M (2008) Self-adhesive resin cements: a literature review. J Adhes Dent 10:251-258. doi:10.3290/j.jad.a13735

10.1186/2196-4351-2-20

Cite this article as: Jardim et al:: The effect of endodontic chemicals on the retention of fiber posts luted using a self-adhesive cement. Applied Adhesion Science 2014, 2:20

Submit your manuscript to a SpringerOpen ${ }^{\circ}$ journal and benefit from:

- Convenient online submission

- Rigorous peer review

- Immediate publication on acceptance

- Open access: articles freely available online

- High visibility within the field

- Retaining the copyright to your article

Submit your next manuscript at $>$ springeropen.com 